\title{
Social-ecological dimensions of forest bark beetle disturbances: Past, present, and future
}

\author{
Jesse Morris' ${ }^{1}$, , J. Clear ${ }^{3}$, S. Cottrell ${ }^{4}$, W. Hansen ${ }^{5}$, K. Mattor ${ }^{4}$, A. Seddon ${ }^{6}$ and H. Seppä ${ }^{7}$ \\ Santa Fe, USA, 2-3 April 2015
}

Since the late 1980s, native bark beetles (Curculionidae: Scolytinae) have caused widespread tree mortality in forests throughout North America and Europe. From a historical perspective the spatial scale and intensity of this disturbance has never been observed before. The outbreaks have been attributed to warm and dry climate conditions, which accelerate beetle reproduction cycles and diminish host tree defenses. During the past two decades, over 47 Mio ha of coniferous forest have been affected in western North America (Raffa et al. 2008).

An international group of ecologists and social scientists concerned with bark beetles met to identify priority research questions about the past, present, and future dynamics of beetle infestations, and the implications for society and the environment. The workshop ran alongside the Western Forest Insect Work Conference (www.wfiwc.org) in which all of the 17 workshop participants gave a short-format oral presentation. These research talks facilitated rich discussions among participants and representatives of several land-management agencies, including the US Forest Service and US Fish and Wildlife Service.

The workshop discussions addressed several major research themes pertaining to the social-ecological dimensions of bark beetle disturbances:

\section{1) Ecological impacts}

Tree mortality in western North America has been caused primarily by the mountain pine beetle (Dedroctonus ponderosae) and spruce beetle (D. rufipennis), while in Europe the spruce bark beetle (Ips typographus) has been most active. A key discussion point was how best to determine the precedence of recent outbreaks through the analysis of lake sediment and peat records. Discussions centered on applications of pollen, non-pollen palynomorphs, insect macrofossils, and biogeochemical proxies to detect past outbreaks with an emphasis on integrating sediment proxies with tree-ring records and forest inventories (Morris et al. 2015).

\section{2) Ecosystem services}

Ecosystem services provide a variety of important benefits to society, though many of these services remain unquantified. Severe beetle outbreaks pose challenges to society, including harmful effects on human health due to diminished air and water quality, by shifting property values, by causing declines in merchantable timber, and by negatively affecting landscape aesthetics causing reductions in tourism revenues (Flint et al. 2009). However, bark beetle disturbances can also lead to increases in the provision of ecosystem services, including improved wildlife viewing and increases in stream flow. These costs and benefits must be managed and measured in the face of change through strategies designed to improve and facilitate resilience (sensu Hollings 1973) and the adaptive capacity of the system. Workshop discussions aimed to identify common metrics, such as carbon biomass, that could aid in assessing the impacts and recovery of

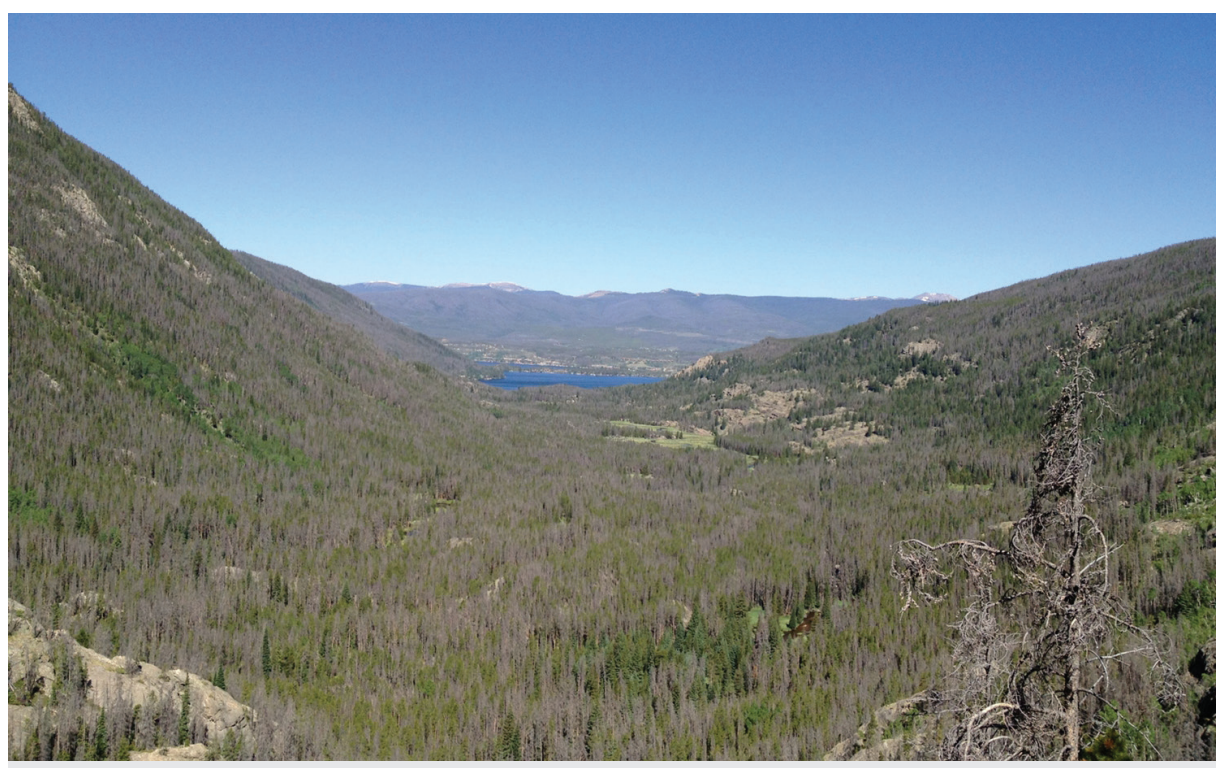

ecosystems from beetle disturbances over multiple spatial and temporal scales.

\section{3) Human behavior}

Of particular interest was how human perspectives shape policy and management response to large-scale outbreaks. For instance, recent studies demonstrate that beetle-impacted forests do not increase fire hazard, yet US management policies still allocate hundreds of millions of dollars annually to reduce fuel loads in beetle-affected forests (Hart et al. 2015). Additionally, changing property values are of concern as communities that were once surrounded by lush forests now find themselves in expansive landscapes of gray, standing dead trees known as "ghost forests" (Fig. 1). However, following salvage logging operations some communities surprisingly realize net increases in real estate values due to enhanced viewsheds (Hansen and Naughton 2013).

Priority research questions identified at the workshop will provide the basis for a forthcoming journal article and a research proposal planned for fall 2015 submission.

\section{ACKNOWLEDGEMENTS}

This workshop was supported through a PAGES workshop award. Additional support was provided by the Mountain Social Ecology Observatory Network funded by a US National Science Foundation award No. DEB-1231233.

\section{AFFILIATIONS}

'Department of Forest, Rangeland, and Fire Sciences, University of Idaho, Moscow, USA

2Department of Geography, Kansas State University, Manhattan, USA

${ }^{3}$ Department of Forest Ecology, Czech University of Life Sciences, Prague, Czech Republic

${ }^{4}$ Warner College of Natural Resources, Colorado State University, Ft. Collins, USA

${ }^{5}$ Department of Zoology, University of Wisconsin, Madison, USA

${ }^{6}$ Department of Biology, University of Bergen, Norway Department of Geosciences and Geography, University of Helsinki, Finland

\section{CONTACT}

Jesse Morris: jlmorris@uidaho.edu

\section{REFERENCES}

Flint C et al. (2009) Environ Manage 43: 1174-1186

Hart S et al. (2015) Proc Nat Aca Sci 112: 4375-4380 Hansen W, Naughton H (2013) Ecol Econ 96: 141-154 Holling CS (1973) Ann Rev Ecol System 4: 1-23 Jeffers E et al. (2015) Quat Sci Rev 112: 17-32 Morris JL et al. (2015) Earth Sci Rev 148: 121-133 Raffa K et al. (2008) BioSci 58: 501-517

Figure 1: View of gray stage lodgepole pine forest, or "ghost forest", resulting from a mountain pine beetle outbreak in the Rocky Mountains, USA. 